\title{
Setting tools for the early assessment of the quality of thawed Pacific oyster (Crassostrea gigas) D-larvae
}

\author{
M. Suquet ${ }^{a,{ }^{*}}$, A. Le Mercier ${ }^{b}$, F. Rimond ${ }^{a}$, C. Mingant ${ }^{a}$, P. Haffray ${ }^{c}$, C. $^{2}$ Labbe $^{d}$ \\ a Ifremer, UMR 6539, PFOM Department, Station Expérimentale d'Argenton, Argenton, France \\ b IUEM, UMR 6539, Lemar, Technopole Brest Iroise, Plouzané, France \\ *: Corresponding author : M. Suquet, email address : $\underline{\text { marc.suquet@ifremer.fr }}$
}

c SYSAAF, Scribe, Rennes, France

dINRA, UR 1037 LPGP, Rennes, France

\begin{abstract}
:
Parameters used to assess the survival of larvae after cryopreservation generally misestimate the damages that prevent larval development. The objectives of the present study were to 1 ) define the reliability of the survival rate, assessed at 2 and 7 days post fertilization, to estimate Pacific oyster larval quality after thawing, and 2) select complementary tools allowing an early and reliable estimation of their quality. Oyster larvae were reared for $25 \mathrm{~h}$ after fertilization at $19{ }^{\circ} \mathrm{C}$ and cryopreserved at early D-stage. Then, thawed larvae were incubated in 2-L beakers. At 2 days post fertilization, the survival rate of thawed Pacific oyster larvae was lower than that of fresh larvae for only one experiment (Experiment 3) among the four identical experiments carried out in this work (Experiments 1-4). By contrast, the survival of thawed larvae, as assessed 7 days after fertilization, was lower than that of fresh larvae for the four experiments. These results confirm that the quality of thawed larvae is lower than that of fresh larvae and that the survival rate, estimated 2 days post fertilization, is not adapted to a reliable estimation of the subsequent development ability of thawed larvae. Then, complementary parameters were tested at 2 days: the movement characteristics (Experiments 1 and 2) and the morphologic features (Experiments 3 and 4) of thawed larvae. Compared to values observed on fresh larvae, the percentage of thawed motile larvae was different for only one experiment (Experiment 2) of the two. Compared to control, a reduced Average Path Velocity (VAP) of larvae (determined at the D-larval stage using a CASA-Computer Assisted Sperm Analysis-system) was observed after thawing for both experiments (Experiments 1 and 2), suggesting the ability of larval movement velocity to assess the decrease of the quality of thawed oyster larvae. Using an ASMA (Automated Sperm Morphology Analysis) device, a lower area of thawed larvae was observed, compared to control and for the two experiments (Experiments 3 and 4). By contrast, the Crofton perimeter of thawed larvae was lower than that of control larvae for only one experiment (Experiment 3) and no significant difference of circularity between fresh and thawed larvae was recorded for Experiments 3 and 4. In conclusion, changes in the movement velocity (assessed by CASA) and in the area (measured by ASMA) of D-larvae allow an early and reliable estimation of the quality of thawed Pacific oyster lanae.
\end{abstract}

Keywords: ASMA; CASA; Crassostrea gigas; Cryopreservation; D-larvae 


\section{Introduction}

Since the first report of the survival of mammalian embryos frozen to $-196^{\circ} \mathrm{C}$ [1], a huge number of domestic and laboratory animals have been produced using embryo cryopreservation. In aquatic animals, while sperm cryopreservation methods are well established $[2,3]$, the preservation of embryos is still far from being achieved. Fish embryos are large reducing the water and cryoprotectant exchanges, composed of different compartments differing in permeability properties, and have a high water content [4]. As a consequence, fish embryo cryopreservation has not yet been successful as this was reported for seabream (Sparus aurata) [5] or Japanese flounder (Paralichthys olivaceus) [6].

In molluscs, the problem is different compared to fish species since oocytes have generally a smaller diameter and a lower yolk content, as reported in Pacific oyster [7]. The cryopreservation of embryos has been studied in a few molluscs such as blue mussel (Mytilus galloprovincialis) [8], Eastern oyster (Crassostrea virginica) [9] and pearl oyster (Pinctada fucata martensii) [10]. However, embryo cryopreservation studies have mainly focused on Pacific oyster (Crassostrea gigas), because of its commercial importance worldwide [11]. The scientific literature was reviewed by Robles et al [4] and PaniaguaChavez et al [9], underlying the problem of embryo survival estimation after cryopreservation. The survival of thawed Pacific oyster embryos was generally estimated by counting the number of motile trochophores, the first stage of bivalve larvae which occurs a few hours after oocyte fertilization [9], [12], [13]. However, the percentage of swimming Pacific oyster larvae measured just after thawing on 9 to $21 \mathrm{~h}$ post fertilization larvae, ranged from 20 to $40 \%$ while only one larva succeeded to settle after $29 \mathrm{~d}$ rearing [13]. Furthermore, $85 \%$ of blue mussel larvae showed active swimming $3 \mathrm{~h}$ after thawing while only half of these larvae had microalgae in their stomach, compared to $80 \%$ for the control group [8]. Both observations suggest that the percentage of motile larvae is not sufficiently integrative, misestimating the damages of thawed larvae or thawed embryos.

Considering this discrepancy, complementary analysis have been developed to precisely estimate embryo or larva quality after thawing including morphological appearance of thawed embryos observed under an optical or an electron microscope [14], fluorescence microscopy [15] and a subjective estimation of movement velocity [13]. Image analysis is a major advance in cell movement, providing a rapid and objective measurement of cell movement velocity [16]. Recently, a new Computer Assisted Sperm Analysis (CASA) system was developed for Image $\mathrm{J}$ : this freely accessible software was primarily designed for fish sperm movement analysis [17]. Motility is considered as a fine parameter to estimate the quality of thawed spermatozoa since it integrates both morphological integrity and cell functionality [18]. A CASA system was used to quantify the decreased quality of thawed sperm in black-lip pearl oyster compared to fresh cells (Pinctada margaritifera) [19]. Concerning embryos or larvae, a CASA system was only used to assess the movement velocity of marine snail (Crepidula fornicata) larvae [20]. Then, an ASMA (Automated Sperm Morphology Analysis) device was successfully used to study the effects of cryopreservation on morphological characteristics of spermatozoa [21].

The aim of the present work was to 1) define the reliability of the survival rate (assessed at day 2 and 7 post fertilization) used to estimate Pacific oyster larval quality after thawing and 2) select complementary tools allowing an early and reliable estimation of the quality of thawed Pacific oyster larvae in comparison with fresh ones.

\section{Materials and methods}

\subsection{Defining the reliability of the survival rate}

Oyster larvae were obtained from three different females according to Song et al. [22] and incubated in $2 \mathrm{~L}$ beakers $\left(100000\right.$ larvae $\left.^{-1}\right)$. Twenty two hours post fertilization at $19^{\circ} \mathrm{C}$, 
larvae were pooled, filtered at $20 \mu \mathrm{m}$ and transferred in $20 \mathrm{~mL}$ seawater. Larvae were cryopreserved, according to Tervit et al [23]: briefly, the pools of larvae were diluted in cryoprotectant (10\% ethylene glycol with 1\% PVP and $200 \mathrm{mM}$ Trehalose in milli Q water, dilution rate: 1:1) and transferred in $0.5 \mathrm{~mL}$ straws (IMV, France; 15000 larvae in each straw). Straws were placed into a program freezer (Kryo10, Planer) which was programmed to cool at $1{ }^{\circ} \mathrm{C} \mathrm{min}{ }^{-1}$ from 0 to $-10^{\circ} \mathrm{C}$ (hold for $5 \mathrm{~min}$ at $-10^{\circ} \mathrm{C}$ ) and at $0.3^{\circ} \mathrm{C} \mathrm{min}^{-1}$ from -10 ${ }^{\circ} \mathrm{C}$ to $-35^{\circ} \mathrm{C}$ at which temperature the straws were plunged in liquid nitrogen. Then, straws were thawed in a water bath $\left(37^{\circ} \mathrm{C}, 10 \mathrm{~s}\right)$ and transferred in $2 \mathrm{~mL}$ seawater.

Thawed larvae were incubated in $2 \mathrm{~L}$ beakers (triplicate) using non limitating density conditions (from 50000 to 150000 in $2 \mathrm{~L}$ beaker), according to a standardized protocol [24].The survival rate of D-larvae (the fully shelled stage observed from $20 \mathrm{~h}$ post fertilization) was estimated after $2 \mathrm{~d}$ of culture at $19^{\circ} \mathrm{C}$. Then, D-larvae were transferred in $5 \mathrm{~L}$ flowthrough culture system (triplicate) and reared using non limitating density conditions (from 10 000 to 100000 in 5 L tank) according to Rico-Villa et al [25]. Larvae survival rate (was estimated after $7 \mathrm{~d}$. Four identical experiments (1 to 4) were carried out using different pools of oocytes but the same protocol : the survival rates of fresh and thawed larvae from the same batch were estimated at $2 \mathrm{~d}$ and $7 \mathrm{~d}$ post fertilization, .

\subsection{Selecting complementary estimation techniques}

The movement characteristics were observed on trochophores just after thawing, during the two first experiments ( 1 and 2). Oysters were concentrated using a $20 \mu \mathrm{m}$ mesh size and 10 $\mu \mathrm{l}$ drops were placed on a glass slide. The horizontal movement of trochophores) was observed at room temperature $\left(20^{\circ} \mathrm{C}\right)$ through a dissecting microscope (Leica MZ 125, 40X objective). The percentage of motile trochophores was visually estimated by counting of embryos (30 embryos for each triplicate). Trochophore velocity was recorded using the same microscope connected to a camera (Sony Exwave HAD). Average Path Velocity (VAP) was measured using a CASA plug-in developed for the Image $\mathrm{J}$ software [17]. Calibration settings used for the two experiments are the following ones: frame rate: 25 frame $\mathrm{s}^{-1}$, larval size range: 1 to 1000 pixels, minimum VAP for motile larvae: $30 \mu \mathrm{m} \mathrm{s}^{-1}$, minimum number of larvae observed: 30 , minimum track length: 25 frames.

Morphological parameters were recorded for D-larvae, $24 \mathrm{~h}$ after thawing during experiments 3 and 4, using a microscope (Leica DMRBE, x20 objective) connected to a camera (Sony CCD). Morphological characteristics were assessed using the software VISILOG 5.1 (Noesis). Larval Crofton perimeter, area and circularity (ranging from 1.0 to 2.8, a value of 1.0 indicating a perfect circle) were measured (minimum: 25 larvae).

\subsection{Statistical analysis}

Percentages (motile trochophores and larval survival) were arcsin square-root transformed prior to analysis. Data were compared using Student t-test.

\section{Results and discussion}

The survival of fresh D-larvae, as estimated $2 \mathrm{~d}$ post fertilization, was different from that of thawed larvae for only one experiment among four (experiment $n^{\circ} 3$ : $P<0.01$; Table 1). According to this result, the survival rate of fresh or thawed Eastern oysters was not different at the D-larval stage [9]. On the contrary, the survival of thawed Pacific oyster larvae, assessed in the present work $7 \mathrm{~d}$ after fertilization, was lower than that of fresh ones, for the four experiments ( $n^{\circ} 1: P<0.01, n^{\circ} 2$ : $\left.P<0.05, n^{\circ} 3: P<0.01, n^{\circ} 4: P<0.05\right)$. Our results confirm that the quality of thawed larvae is lower than that of fresh ones. Furthermore, the $D$ - 
larval rate assessed $2 \mathrm{~d}$ after fertilization is not adapted to a reliable estimation of the subsequent development of thawed larvae since it does not reflect larval mortality observed at $7 \mathrm{~d}$ post fertilization. As suggested by Robles et al [4], the D-larval rate does not provide information on fine cell damages that may hinder embryo development, so confirming complementary parameters must be used.

Depending on experiment, the percentage of thawed motile trochophores was not different (experiment $n^{\circ} 1$ ) or lower (experiment $n^{\circ} 2$ : $P<0.05$ ) than that observed on fresh ones (Fig. 1). On the other hand and compared to control, a reduced VAP was observed after thawing for both experiments ( 1 and 2 : $P<0.001$; Fig. 1). A low movement velocity of thawed Pacific oyster embryos was subjectively assessed by Ususki et al. [13]. Our results suggest the ability of trochophore movement velocity to assess the decrease of the survival rate of thawed oyster larvae.

For both experiments ( 3 and 4: $\mathrm{P}<0.001$ ), a lower area of cryopreserved larvae was observed compared to control (Fig. 2). A significant decrease of thawed European eel (Anguilla anguilla) sperm area was also detected [21]. The Crofton perimeter of cryopreserved larvae was lower $(P<0.01)$ than that of control larvae but only for experiment 3 (Fig. 2). Then, no significant difference of circularity between fresh and cryopreserved larvae was recorded for both experiments. Since a lower area of cryopreserved larvae was observed for both experiments, this parameter is well adapted to a reliable estimation of the decrease of thawed larval survival. The recent development of a freely available ASMA plugin for Image J software [26] would facilitate the measurement of cell morphological parameters after its calibration to oyster larvae.

In conclusion, changes in the movement velocity of trochophores (assessed by CASA) and in the area of D-larvae (measured by ASMA) allow an early and reliable estimation of the quality of thawed Pacific oyster larvae.

\section{Acknowledgments}

The authors wish to thank Serean Adams (Cawthron Institute, New Zealand) and Robin Tervit (Ag Research, New Zealand) for advices on the cryopreservation protocol. We also acknowledge Isabelle Queau (Ifremer) and Luc Lebrun (Ifremer) for oyster and algae management. The present research was supported by the national projects Creche (Ofimer 136/08/C), European Union (FEP 30906-2009) and Cryoaqua (GIS IBISA). 


\section{References}

[1] Whittingham DG, Leibo SP, Mazur P. Survival of mouse embryos frozen to $-196^{\circ}$ and $269^{\circ} \mathrm{C}$. Science 1972;178: 411-4.

[2] Gwo JC. Cryopreservation of aquatic invertebrate semen: a review. Aquac Res 2000;31: 259-271.

[3] Suquet M, Dreanno C, Fauvel C, Cosson J, Billard R. Cryopreservation of sperm in marine fish. Aquac Res 2000;31: 231-43.

[4] Robles V, Cabrita E, Acker JP, Herraez P. Embryo cryopreservation: What we know until now. In:Reproductive aquaculture, Cabrita E, Robles V, Herraez P (Eds.), CRC Press, 2009, pp. 265-294.

[5] Cabrita E, Robles V, Wallace JC, Sarasquete MC, Herraez MP. Preliminary studies on the cryopreservation of gilthead seabream (Sparus aurata) embryos. Aquaculture 2006;251: 245-55.

[6] Edashige K, Seki S, Saida N, Valdez DM, Hara T, Kasai M. Issues in the cryopreservation of Japanese flounder. Cryobiol 2006;53: 399.

[7] Lango-Reynoso F, Chavez-Villalba J, Cochard J L, Le Pennec M. Oocyte size, a means to evaluate the gametogenetic development of the Pacific oyster Crassostrea gigas (Thunberg). Aquaculture 2000;190: 183-199.

[8] Wang H, Li X, Wang M, Clarke S, Gluis M, Zhang Z. Effects of larval cryopreservation on subsequent development of the blue mussel, Mytilus galloprovincialis Lamarck. Aquac Res 2011;42: 1-8.

[9] Paniagua-Chavez CG, Buchanan JT, Supan JE, Tiersch TR. Cryoperservation of sperm and larvae of the Eastern oyster. In: Cryopreservation in aquatic species. Tiersch TR, Mazik PM (Eds.), WAS, 1998, pp. 230-9.

[10] Choi YH, Chang YJ. The influence of cooling rate, developmental stage, and the addition of sugar on the cryopreservation of larvae of the pearl oyster Pinctada fucata martensii. Cryobiol 2003;46:190-3.

[11] Food and Agricultural Organization. Yearbook of Fisheries statistics. Summary tables. ftp://ftp.fao.org/fi/STAT/summaryl

[12] Chao NH, Lin TT, Chen YJ, Hsu HW, Liao IC. Cryopreservation of late embryos and early larvae in the oyster and hard clam. Aquaculture 1997;155: 31-44.

[13] Usuki $H$, Hamaguchi $M$, Ishioka $H$. Effects of developmental stage, seawater concentration and rearing temperature on cryopreservation of Pacific oyster Crassostrea gigas larvae. Fish Sci 2002;68: 752-62.

[14] Renard P. Cooling and freezing tolerances in embryos of the Pacific oyster, Crassostrea gigas: methanol and sucrose effects. Aquaculture 1991;92: 43-57.

[15] Paniagua-Chavez CG, Jenkins J, Segovia M, Tiersch T. Assessment of gamete quality for the eastern oyster (Crassostrea gigas) by use of fluorescence dyes. Cryobiol 2006;53: 128-38.

[16] Cosson J, Billard R, Cibert C, Dreanno C, Linhart O, Suquet M. Movements of fish sperm flagella studied by high speed videomicroscopy coupled to computer assisted image analysis. Pol Arch Hydrobiol 1997;44: 103-13.

[17] Wilson-Leedy JG, Ingermann RL. Development of a novel CASA system based on open source software for characterization of zebrafish sperm motility parameters. Theriogenol 2007;67: 661-72.

[18] Cosson J. The motility apparatus of fish spermatozoa. In: Fish spermatology, Alavi $\mathrm{MH}$, Cosson J, Coward K, Rafiee G (Eds.), Alpha Science, 2008, pp. 281-316.

[19] Lyons L, Jerry DR, Southgate PC. Cryopreservation of black-lip pearl oyster (Pinctada margaritifera, L.) spermatozoa: Effects of cryoprotectants on spermatozoa motility. J Shellfish Res 2005;24: 1187-90.

[20] Hilbish TJ, Sasada K, Eyster LS, Pechenik JA. Relationship between rates of swimming and 
growth in veliger larvae: genetic variance and covariance. J Exp Mar Biol Eco 1999;239: 18393.

[21] Asturiano JF, Marco-Jimenez F, Penaranda DS, Garzon DL, Pérez L, Vicente JS, Jover $M$. Effect of sperm cryopreservation on the European eel sperm viability and spermatozoa morphology. Reprod Dom Anim 2007;42: 162-6.

[22] Song YP, Suquet M, Quéau I, Lebrun L. Setting of a procedure for experimental fertilisation of Pacific oyster (Crassostrea gigas) oocytes. Aquaculture 2009;287: 311-4.

[23] Tervit HR, Adams SL, Roberts RD, Mc Gowan LT, Pugh PA, Smith JF, Janke AR. Successful cryopreservation of Pacific oyster (Crassostrea gigas) oocytes. Cryobiol 2005;51: $142-51$.

[24] Suquet M, Amourda C, Mingant C, Quéau I, Lebrun L, Brizard R. Setting of a procedure for experimental incubation of Pacific oyster (Crassostrea gigas) embryos. Aquaculture 2007; 273: 503-8.

[25] Rico-Villa B, Woerther P, Mingant C, Lepiver D, Pouvreau S, Hamon M, Robert R. A flow-through rearing system for ecophysiological studies of Pacific oyster, Crassostrea gigas, larvae. Aquaculture 2008;282: 54-60.

[26] Butts IAE, Ward MAR, Litvak MK, Pitcher TE, Alavi SMH, Trippel EA, Rideout RM.

Automated sperm head morphology analyzer for open-source software. Theriogenol 2011;76: 1756-61. 
Tables

\begin{tabular}{|c|c|c|c|c|c|c|c|c|}
\hline Experiment $\mathrm{n}^{\circ}$ & 1 & & 2 & & 3 & & 4 & \\
\hline Type of larvae & Fresh & Thawed & Fresh & Thawed & Fresh & Thawed & Fresh & Thawed \\
\hline Larval survival at $7 \mathrm{~d}(\%)$ & $42.9 \pm 6.1^{\mathrm{a}}$ & $\begin{array}{l}4.0 \pm 0.8 \\
b\end{array}$ & $85.1 \pm 13.0^{a}$ & $22.9 \pm 13.7^{b}$ & $12.5 \pm 1.9^{\mathrm{a}}$ & $5.6 \pm 1.9^{b}$ & $9.7 \pm 3.1^{a}$ & $2.2 \pm 1.1^{b}$ \\
\hline
\end{tabular}

Table 1. Effect of cryopreservation on larval survival at $2 \mathrm{~d}$ and $7 \mathrm{~d}$ post fertilization (mean $\pm \mathrm{SD}$; different letters refer to significantly different results within each experiment and within each day after fertilization) 


\section{Figures}

Fig. 1. Effect of cryopreservation on the movement characteristics of Pacific oyster trochophores (estimated using a CASA device; mean \pm SD; asterisks refer to significantly different results: * $\left.<0.05,{ }^{\star * *}<0.001\right)$.

Fig 2. Effect of cryopreservation on the morphological characteristics of Pacific oyster D-larvae (estimated using an ASMA device; mean \pm SD; asterisks refer to significantly different results: $\left.{ }^{\star \star}<0.01,{ }^{\star \star \star}<0.001\right)$. 

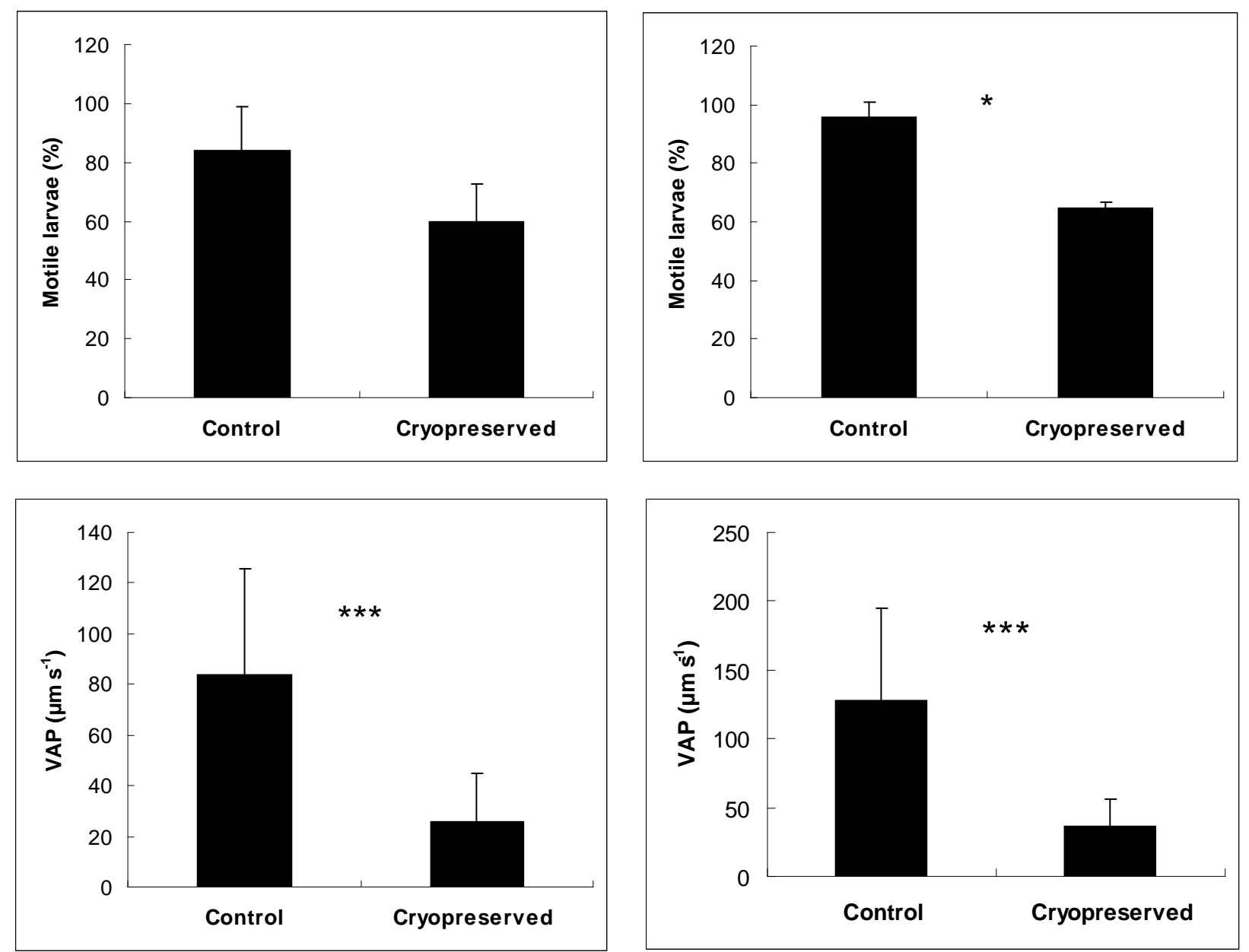

Experiment 1

Experiment 2 

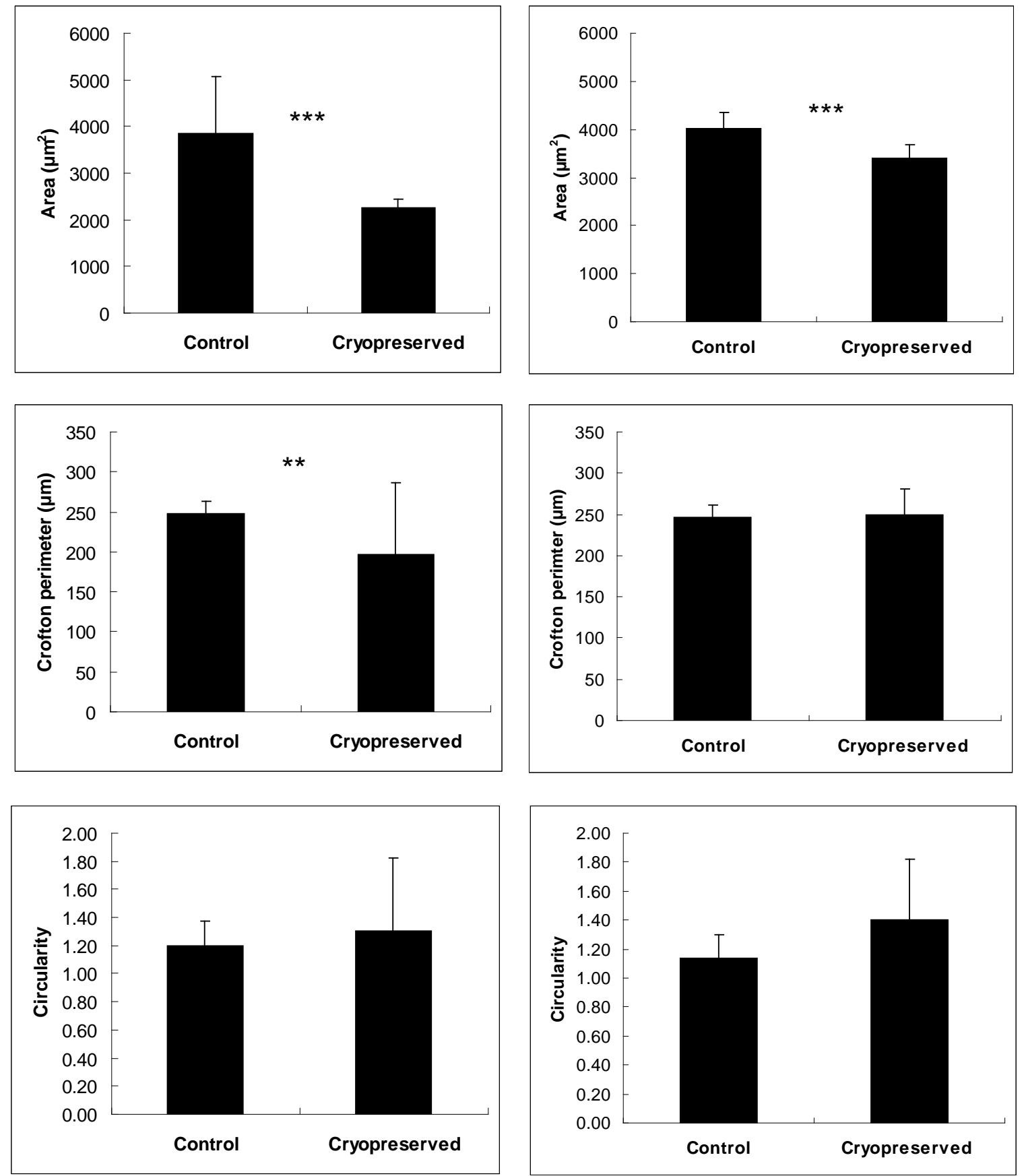

Experiment 3

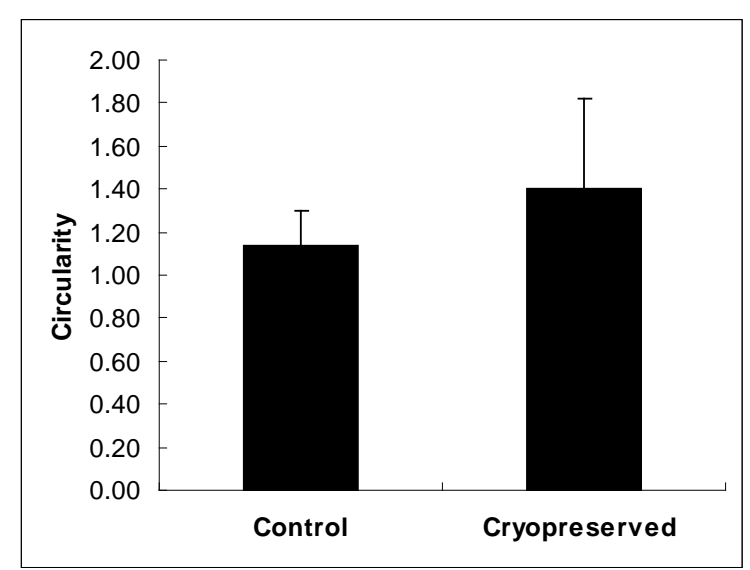

Experiment 4 